\title{
LASKAR SANTRI PEJUANG NEGERI: Rekam Jejak Laskar Hizbullah dalam Pertempuran 10 November 1945 di Surabaya
}

\author{
Jumeroh Mulyaningsih \\ Dedeh Nur Hamidah \\ Jurusan Sejarah Peradaban Islam IAIN Syekh Nurjati Cirebon
}

\begin{abstract}
ABSTRAK
Salah satu perjuangan fisik dalam menghadapi tentara sekutu setelah proklamasi kemerdekaan Indonesia adalah perjuangan yang dilakukan oleh sekelompok pejuang Islam, yakni Laskar Hizbullah. Anggota Hizbullah memiliki semangat kebangsaan dan spirit Islam yang tinggi. Dalam hal ini perlu menjadi ingatan kolektif bahwa peran Laskar Hizbullah cukup besar dalam mempertahankan kemerdekaan Indonesia. Laskar Hizbullah dibentuk sebagai laskar kesatuan perjuangan semi militer dari kelompok Islam yang dilandasi dengan niat jihad fi sabilillah, berjuang menegakkan agama dan Negara. Laskar Hizbullah berperan aktif dalam pertempuran 10 November 1945 di Surabaya. Kedahsyatan pertempuran tersebut tidak terlepaskan dari Resolusi Jihad, 22 Oktober 1945. Surabaya menjadi melting pot Laskar Hizbullah dari berbagai daerah, pertempuran yang terjadi cukup menghentakkan pihak sekutu. Apa yang terjadi di Surabaya pada Oktober-November 1945 menjadi kisah nyata, kontribusi besar Laskar Hizbullah yang bergerak secara gigih, dengan kekuatan lahir batin serta mental baja untuk mempertahankan kemerdekaan Indonesia.
\end{abstract}

Kata kunci: Laskar Hizbullah, Resolusi Jihad, 10 November 1945.

\section{A. Pendahuluan}

Berangkat dari buah pikir Dr. Setia Budi (E.FE. Douwes Dekker) yang menyatakan bahwa "Jika tidak karena pengaruh dan didikan agama Islam, maka patriotisme bangsa Indonesia tidak akan sehebat seperti yang diperlihatkan oleh sejarahnya hingga mencapai kemerdekaannya”. Dalam hal ini perlu menjadi ingatan kolektif bahwa peran pesantren serta umat Islam cukup besar dalam pencapaian kemerdekaan Indonesia, karena para tokoh 
pergerakan nasional tidak dapat dilepaskan dari dunia pesantren dan spirit Islam.

KH. Hasyim Asy'ari, KH. Abbas Abdul Jamil ${ }^{1}$, KH. Wahab Hasbullah, KH. Wahid Hasyim, dan lain-lain, merupakan tokoh-tokoh Islam yang lahir dari rahim pesantren yang memainkan peranan penting dalam mengawal bangsa. Resolusi Jihad yang digelorakan KH. Hasyim Asy'ari pada 22 Oktober 1945 menjadi pemantik semangat dan menginspirasi para pejuang untuk terjun ke medan pertempuran. Pertempuran terjadi di berbagai daerah secara serempak, demi mempertahankan kemerdekaan Indonesia. Pada November 1945 menjadi bukti nyata bahwa ulama-santri telah berjuang demi tegaknya negeri ini.

Ulama-santri telah menjadi simbol perlawanan terhadap penjajah. Hal ini dibuktikan saat kemerdekaan RI diproklamirkan, Laskar Hizbullah ${ }^{2}$ secara moral maupun organisasional dalam keadaan utuh dan penuh semangat juang tinggi. Secara organisasional, Hizbullah dalam keadaan solid hingga masa-masa setelah proklamasi kemerdekaan. Bahkan, Laskar Hizbullah menjadi salah satu kesatuan bersenjata yang paling siap dalam menyongsong satu era baru yakni era Revolusi kemerdekaan.

Rasanya Tidak mudah menemukan jejak sejarah yang bermuatan "Peran ulama-santri dalam kemerdekaan Indonesia" dalam buku-buku sejarah yang tersebar di rak-rak perpustakaan. Seakan peran ulama-santri dalam

${ }^{1}$ Basis kekuatan laskar yang dibangun oleh KH. Abbas menjadi pilar penting bagi tercetusnya revolusi November 1945 di Surabaya. Peristiwa tersebut terbukti setelah KH. Hasyim Asy'ari mengeluarkan Resolusi Jihad. Hubungan KH. Abbas dengan KH. Hasyim Asy'ari memang sudah lama terjalin, terlihat ketika pertama kali didirikannya Pondok Pesantren Tebuireng, KH. Abbas banyak memberikan perlindungan, terutama saat diganggu oleh penjahat setempat, yang merasa terusik oleh kehadiran Pesantren Tebuireng. Lihat Khoirul Anam, Kisah Ulama: Berjuang dan Mengawal Bangsa, Jakarta: Pustaka Compass, 2015, hlm. 48 .

2 Laskar Hizbullah dibentuk untuk mempersiapkan kemerdekaan Indonesia dan mempertahankannya. Laskar ini secara khusus beranggotakan pemuda-pemuda Islam se-Jawa dan Madura. Lihat Zainul Milal Bizawie, Laskar Ulama-Santri \& Resolusi Jihad Garda Depan Menegakkan Indonesia (1945-1949), Jakarta: Pustaka Compass, 2014, hlm. 120. 
kemerdekaan Indonesia hanya menjadi ingatan sebagian kalangan tertentu saja. Pelenyapan dokumen-dokumen terkait keterlibatan laskar ulama-santri yang tergabung dalam Laskar Hizbullah, makin mensenyapkan arti penting Resolusi Jihad saat mempertahankan kemerdekaan Indonesia. Sehingga peran laskar ulama-santri hanya terdengar begitu lirih di pesantren-pesantren dan pedesaanpedesaan yang makin lama makin lenyap.

Setelah penetapan Hari Santri pada 22 Oktober 2015 oleh Presiden Joko Widodo, kisah-kisah perjuangan ulama-santri yang tergabung dalam Laskar Hizbullah perlu dituliskan ulang dengan perspektif sejarah pengetahuan yang lebih mendalam, karena perjuangannya memiliki peran strategis dalam mempertahankan kemerdekaan. Peran Laskar Hizbullah yang telah berjuangan gigih dan mengabdi untuk bangsa harus dipublikasikan secara luas sebagai cermin untuk mengawal bangsa dan menjadi teladan bersama.

Penulis tergugah untuk menelusuri episode sejarah, menyusun puzzlepuzzle sejarahnya yang masih berserakan yang hampir satu abad nyaris dipinggirkan. Sejarah tidak diarahkan untuk membangun kuasa pengetahuan yang cenderung menonjolkan satu kekuatan. Hal tersebut, perlu adanya kesadaran akan saling berkelindannya antara penulisan sejarah dengan kekuasaan. Dengan menuliskan kembali sejarah yang mengupas kiprah ulamasantri dalam kemerdekaan Indonesia, penulis juga berperan dalam membangun pemahaman sejarah lain yang selama ini dijadikan sejarah resmi negara.

\section{B. Santri Menjadi Komponen Utama Laskar Hizbullah}

Pergerakan ulama-santri melawan kolonial bermuara pada terbentuknya Laskar Hizbullah. Pada era politik etis kolonial Belanda, kalangan pesantren begitu terpinggirkan, sehingga tidak mendapatkan perhatian dari kebijakan pendidikan, bahkan terkesan dirugikan. Meskipun demikian, karakteristik pendidikan ala pesantren tetap dipertahankan serta menjadi ciri khas kalangan 
Islam. Meski tidak mendapatkan perhatian, justru pesantren telah membangun dan menjaga suatu gerakan menjahit bangsa ini melalui jejaring ulama baik lokal maupun internasional. Berdirinya NU merupakan hasil dari rangkaian jejaring ulama dan santri tersebut. Tradisi perlawanan terhadap kolonial terus dijaga oleh ulama dan melalui NU serta MIAI atau Masyumi bahkan perjuangan dan pergerakan melawan kolonial tersebut lebih efektif karena mapannya struktur NU dan basis massanya menyebar di pedesaan. Jepang memahami, kalangan Islam sangat penting dan memiliki posisi strategis, karenanya Jepang berupaya merangkul Islam khususnya dunia pesantren, dalam konteks inilah Laskar Hizbullah dibentuk untuk mempersiapkan kemerdekaan Indonesia dan mempertahankannya.

Laskar Hizbullah secara khusus beranggotakan pemuda-pemuda Islam se-Jawa dan Madura. Pada latihan pertama di Cibarusa, Bogor, yang diikuti 500 orang pemuda muslim tercatat sejumlah nama kyai dari pondok pesantren seperti KH. Musthofa Kamil (Banten), KH. Mawardi (Solo), KH. Zarkasi (Ponorogo), KH. Mursyid (Pacitan), KH. Syahid (Kediri), KH. Abdul Halim (Majalengka), KH. Thohir Basuki (Surakarta), KH. Roji'un (Jakarta), KH. Munasir Ali (Mojokerto), KH. Wabib Wahab (Jombang), KH. Hasyim Latif (Surabaya), KH. Zainuddin (Besuki), Sulthan Fajar (Jember), KH. Abdullah Abbas (Cirebon). ${ }^{3}$

Pelatihan dipimpin oleh Kapten Yanagawa serta dibantu oleh 20 orang chudancho (perwira Peta). Ajang latihannya belangsung di lapangan seluas 20 hektar dekat kebun karet. Beberapa bedeng bambu dan kayu disediakan untuk asrama, ruang kelas, mushola, dapur, serta ruang serbaguna. Pelatihan militer dimulai dari taisho (senam pagi) dan kakeashi (lari-lari kecil pemanasan) dilanjutkan dengan kyoren (latihan tempur). Di bawah pengawasan perwiraperwira Jepang dan Peta latihan dilangsungkan dengan penuh disiplin. Latihan

\footnotetext{
${ }^{3}$ Ibid., hlm. 139.
} 
dilaksanakan berulang-ulang, peserta dibagikan mokuju (senapan tiruan yang terbuat dari kayu jati) atau takeyari (bambu runcing). Selain dipakai dalam latihan baris berbaris, senjata-senjata sederhana tersebut dipakai dalam latihan peperangan. ${ }^{4}$

Tahap berikutnya dilatih juga sento kyoren yang meliputi latihan tambahan berupa macam-macam teknik bertiarap (fuse), merangkak (hofuku), formasi icirit (formasi pasukan bergerak satu persatu ke belakang), teknik mengintai (sekko), hingga serangan banzai, dan serangan komando (kirikumi). Diajarkan pula kemampuan meracik bom molotov, dan bom peledak lainnya. Meskipun pelatihan pasukan Hizbullah tidak disertai senjata sungguhan, namun pelaksanaannya tertib teratur serta berdisiplin tinggi. Terbukti pelatihan ini meningkatkan kemampuan militer para pemuda Indonesia umumnya, khususnya anggota-anggota pasukan Hizbullah. Jepang juga memperkenalkan teknik militer gerilya, suatu hal yang tidak digunakan oleh pasukan-pasukan kolonial Belanda dan Inggris. ${ }^{5}$

Berbeda dengan pola pelatihan terhadap pasukan Peta, Yanagawa melarang hukuman berupa memukul secara fisik karena dianggap dapat menyinggung perasaan umat muslim. Sebagai gantinya bentuk hukuman yang diberikan dalam pelatihan Hizbullah berupa kegiatan sumo (gulat tradisional Jepang).

Setelah pendidikan dan latihan selesai pada 20 Mei 1945, komandan Laskar Hizbullah KH. Zainul Arifin menutup latihan tersebut dalam sebuah upacara yang dihadiri para pimpinan Masyumi. Setelah itu, para peserta latihan kembali ke daerahnya masing-masing dengan tugas merekrut serta melatih

${ }^{4}$ Ario Helmy, KH. Zainul Arifin Pohan Panglima Santri Ikhlas Membangun Negeri, Tangerang: Pustaka Compass, 2015, hlm. 46-47.

${ }^{5}$ Ibid., hlm. 47. 
anggota baru di kampung mereka masing-masing atau di pesantren-pesantren. Berpindahnya pelatihan ke kawasan pedesaan dan pesantren-pesantren maka keanggotaan Hizbullah semakin bertambah besar dengan ditaksir jumlahnya mencapai 50.000 anggota. Jumlah serta materi pelatihan tersebut secara kualitas, personil Hizbullah dapat dikatakan memiliki kemampuan teknik militer yang lebih baik dibandingkan dengan barisan-barisan militer lain yang dibentuk pada masa Jepang, kecuali dengan satuan militer seperti Peta dan Heiho. $^{6}$

\section{Seruan Jihad Menyambut Pertempuran 10 November 1945}

Sebagai kota terbesar kedua setelah Jakarta, Surabaya sangat heterogen. Di kota ini ada kelompok sosial masyarakat seperti priyayi mapan, kaum intelektual-kritis, golongan Islam (baik kelompok Islam tradisional maupun modernis), kelompok sosialis-kiri, rakyat jelata, dan sebagainya. Secara historis, Jawa Timur dan Surabaya telah menjadi basis paling kuat kaum Islam tradisional. Di wilayah ini dikenal sebagai kantong utama bagi pesantrenpesantren. Surabaya merupakan melting pot (melebur menjadi satu) bagi para Laskar Hizbullah. $^{7}$

Kantor pusat pengurus NU sejak awal berdirinya hingga memasuki masa Revolusi kemerdekaan tetap berbasis di Surabaya. Ketika Jepang menyelenggarakan pelatihan bagi perwira Hizbullah di wilayah Jawa dan Madura, peserta dari Jawa Timur mengirim jumlah yang paling banyak. Baik para kyai dan santri di pesantren yang menjadi perwira Hizbullah memiliki pengaruh terhadap para anak buah dan masyarakat di mana mereka tinggal. Peran para kyai dan santri sebagai pejuang dan sukarelawan bukan hanya penduduk Surabaya, melainkan berdatangan dari kota-kota lain di sekitar

${ }^{6}$ Zainul Milal Bizawie, Laskar Ulama-Santri \& Resolusi Jihad Garda Depan Menegakkan Indonesia (1945-1949), Op. cit., hlm. 142.

${ }^{7}$ Ibid., hlm. 198. 
Surabaya, seperti Gresik, Jombang, Sidoarjo, Pasuruan, Bondowoso, Ponorogo, Mojokerto, Malang, Madura, Cirebon dan Bandung. ${ }^{8}$

Laskar Hizbullah dan Sabilillah menjadi bukti historis yang tidak terbantahkan dalam membela RI. Di antara mereka muncul KH. Masykur dan KH. Zainul Arifin, KH. Muhammad Hasyim Latief, dan KH. Munasir Ali, KH. Wahid Hasyim dan KH. Masykur yang terlibat secara intens proses terwujudnya kemerdekaan RI bersama Soekarno, Hatta, Syahrir, Agus Salim, Kahar Muzakkir, Mas Mansyur dan lainnya. ${ }^{9}$

Dengan adanya pendaratan Tentara Sekutu dan NICA di Jakarta, Semarang dan Surabaya, serta Sumatra, pada 29 September 1945, Pemerintah Republik Indonesia tidak melakukan perlawanan yang nyata terhadap tindakan NICA dan Balatentara Jepang. Maka, Rapat Besar wakil-wakil daerah (Konsul 2) Perhimpunan Nahdlatul Ulama seluruh Jawa dan Madura pada 21-22 Oktober 1945 mengajukan Resolusi Jihad $^{10}$ pada pemerintah Republik Indonesia yang isinya sebagai berikut.

Memohon dengan sangat kepada Pemerintah Republik Indonesia, supaya menentukan suatu sikap dan tindakan yang nyata serta sepadan terhadap tiaptiap usaha yang akan membahayakan kemerdekaan Agama dan Negara Indonesia, terutama terhadap pihak Belanda dan kaki tangannya. Supaya memerintahkan melanjutkan perjuangan bersifat "Sabilillah" untuk tegaknya Negara Republik Indonesia Merdeka dan Agama Islam. ${ }^{.1}$

Resolusi Jihad di atas, pada saat terbentuknya Partai Islam Indonesia Masyumi, di Yogyakarta 7 November 1945, Rabu Pon, 1 Dzulhijjah 1364, menjadi Resolusi Jihad dari Mu'tamar Umat Islam Indonesia. Antara lain:

${ }^{8}$ Ibid.

${ }^{9}$ Ibid., hlm. 205.

${ }^{10}$ Jihad adalah pengerahan seluruh potensi (dalam menangkis serangan musuh), dalam Islam dinyatakan: Segala bentuk usaha maksimal untuk penerapan ajaran Islam, pemberantasan kejahatan, kedzaliman, baik terhadap diri pribadi maupun masyarakat. Lihat Tim Penyusun, Ensiklopedi Islam Indonesia, Jakarta: PT. Ikhtiar Baru Van Houve, 1993, hlm. 315.

${ }^{11}$ Ahmad Mansur Suryanegara, Api Sejarah 2, Bandung: Salamadani, 2010, hlm. 201. 
Bahwa tiap tiap bentuk penjajahan adalah suatu kedzaliman yang melanggar perikemanusiaan dan nyata diharamkan oleh Agama Islam, maka 60 Miliun Kaum Muslimin Indonesia Siap Berjihad Fi Sabilillah. Perang di jalan Allah untuk menentang tiap tiap Penjajahan.

Memperkuat pertahanan Negara Indonesia dengan berbagai usaha, maka disusunlah suatu barisan yang diberi nama Barisan Sabilillah, di bawah pengawasan Masyumi. Barisan ini adalah menjadi Barisan Istimewa dari Tentara Keamanan Rakyat-T.K.R $R^{12}$.

Keputusan Mu'tamar Umat Islam Indonesia di bidang organisasi kesenjataan di kalangan Ulama dengan nama Sabilillah di atas sebagai kelanjutan dari terbentuknya 68 Batalyon Tentara Pembela Tanah Air - Peta, dan 400.000 barisan Hizbullah pada masa pendudukan Jepang 1942-1945 M.

Peran serta para kyai dalam membakar semangat dan moril terlihat ketika berusaha memaknai perjuangan membela tanah air sebagai jihad $f i$ sabililllah. Sebuah fatwa jihad, terlebih dahulu beredar sebelum terlahirnya Resolusi Jihad yang diputuskan lewat rapat para kyai di Surabaya. Fatwa yang ringkasnya dimuat dalam Harian Kedaulatan Rakyat pada 20 November 1945, ditandatangani oleh KH. Hadratusyeikh Hasyim Asy'ari pada 17 September 1945.

Gema perjuangan berupa Resolusi Jihad, yang digelorakan Hadratusyeikh Hasyim Asy'ari menjadi catatan sejarah yang berhasil memantik semangat warga untuk berjuang mengorbankan jiwa raga. Resolusi yang digemakan pada 22 Oktober 1945 menjadi kekuatan yang meningkatkan daya juang warga di sekitar Jawa Timur. Resolusi Jihad menyatakan bahwa:

1. Kemerdekaan Indonesia yang telah diproklamirkan pada 17 Agustus 1945 wajib dipertahankan.

2. Republik Indonesia sebagai satu-satunya pemerintahan yang sah wajib dibela dan diselamatkan meskipun meminta pengorbanan harta dan jiwa.

${ }^{12}$ Teks tersebut sesuai dengan Harian Kedaulatan Rakyat No. 38 yang dimuat pada Jum'at Kliwon, 9 November 1945 (Pen. dengan menggunakan ejaan yang telah disempurnakan). 
3. Musuh-musuh RI, terutama Belanda yang datang kembali membonceng tugas-tugas tentara sekutu (Amerika-Inggris), dalam hal tawanan perang bangsa Jepang, tentulah akan menggunakan kesempatan politik dan militer untuk kembali menjajah Indonesia.

4. Umat Islam, terutam warga NU wajib mengangkat senjata melawan Belanda dan kawan-kawannya yang hendak kembali menjajah Indoensia.

5. Kewajiban tersebut adalah "jihad" yang menjadi kewajiban bagi tiaptiap umat Islam (fardhu ain) yang berada dalam jarak radius $94 \mathrm{KM}$ (yakni jarak di mana umat Islam boleh melakukan sholat jama' dan qoshor). Adapun bagi mereka yang berada di luar jarak tersebut berkewajiban membantu saudara-saudaranya yang berada dalam jarak tersebut. ${ }^{13}$

Berpijak pada fatwa jihad ini, kemudian dikukuhkan oleh rapat para kyai pada tanggal 21-22 Oktober 1945. Mereka adalah para perwakilan Nahdlatul Ulama se-Jawa dan Madura berkumpul di kantor Hofdsbestuur Nahdlatul Ulama atau HB NU sekarang Pengurus Besar Nahdlatul Ulama di jalan Bubutan IV No. 2 Surabaya. Di tempat inilah, para kyai berkesempatan untuk membahas situasi perjuangan dan membicarakan upaya mempertahankan kemerdekaan Indonesia. Di akhir pertemuan tersebut, Pengurus Besar Nahdlatul Ulama mengeluarkan sebuah Resolusi Jihad sekaligus menguatkan Fatwa Jihad Rais Akbar NU, KH. Hasyim Asy'ari.

\section{Respon Laskar Hizbullah atas Seruan Resolusi Jihad}

Resolusi Jihad tidak hanya sebagai pengobar semangat ulama-santri, tetapi juga bertujuan mendesak pemerintah agar segera menentukan sikap

${ }^{13}$ Munawir Aziz, Pahlawan Santri Tulang Punggung Pergerakan Nasional, Ciputat: Pustaka Compass, 2016, hlm. 21-22. 
melawan kekuatan asing yang ingin menggagalkan kemerdekaan. Banyak terjadi pertempuran-pertempuran yang melibatkan para kyai dan santri yang tergabung dalam Laskar Hizbullah dan Sabilillah. Di saat tentara negara belum efektif terutama jalur komandonya, laskar ulama-santri telah sigap menghadapi berbagai ancaman yang akan terjadi. Bahkan konsolidasi dan jalur komando Laskar Hizbullah dengan dukungan struktur NU dan Masyumi begitu masif hingga kepedesaan. ${ }^{14}$

Resolusi Jihad ini menjadi pegangan bagi kalangan Islam dalam melakukan perjuangan menghadapi NICA-Belanda dan pasukan Inggris. Konsul-konsul yang hadir dalam pertemuan di Bubutan itu juga memiliki tugas dan amanah untuk menyebarkan resolusi ini kepada umat Islam di daerahnya masing-masing. Salinan keputusan Resolusi Jihad ini juga dikirimkan kepada presiden Soekarno, pimpinan Angkatan Perang Indonesia, dan kepada Markas Tinggi Hizbullah dan Sabilillah. ${ }^{15}$

Resolusi Jihad ini memiliki tujuan ganda; pertama, sebagai bahan untuk "mempengaruhi" pemerintah dan agar segera menentukan sikap melawan kekuatan-kekuatan asing yang terindikasi hendak menggagalkan kemerdekaan. Kedua, jika himbauan yang ditujukan kepada pemerintah itu tidak terwujud maka resolusi akan bisa dijadikan sebagai pegangan moral bagi Hizbullah, Sabilillah, serta badan perjuangan lain untuk menentukan sikap dalam melawan kekuatan asing. ${ }^{16}$

Resolusi Jihad memiliki implikasi yang sangat besar bagi perjuangan revolusioner umat Islam Indonesia dalam melawan penjajah dan kolonialisme. Selain Hizbullah, pasca seruan jihad dibentuklah pasukan Sabilillah yang

${ }^{14}$ Zainul Milal Bizawie, Masterpiece Islam Nusantara Sanad dan Jejaring UlamaSantri (1830-1945), Op. cit., hlm. 27.

${ }^{15}$ Saifuddin Zuhri, Berangkat Dari Pesantren, Jakarta: Gunung Agung, 1987, hlm. 257.

16 Zainul Milal Bizawie, Laskar Ulama-Santri \& Resolusi Jihad Garda Depan Menegakkan Indonesia (1945-1949), Op. cit., hlm. 210. 
langsung merespon ajakan perang suci ini. ${ }^{17}$ Para kyai berduyun-duyun mengirimkan para santri untuk bergabung dengan Hizbullah, Sabilillah, dan badan-badan perjuangan lain. Bahkan tidak hanya datang dari kawasan Jawa Timur saja, tetapi cukup banyak kesatuan Hizbullah, laskar-laskar, dan para santri dari pesantren-pesantren di Jawa Tengah dan Jawa Barat turut hadir dan memperkuat barisan pertahanan para pejuang di Surabaya.

Laskar Hizbullah dan Sabilillah sebagai sayap militer umat Islam mulai berduyun-duyun memasuki Surabaya untuk menghadang kembalinya sang penjajah. Di antara alumnus kedua laskar yang ikut bertempur di Surabaya itu adalah KH. Munasir Ali, KH. Yusuf Hasyim, KH. Baidowi, KH. Mukhlas Rowi, dan KH. Sulaman Samsun. Tidak berbeda dengan Jawa Timur bagian Selatan, seruan jihad melawan kolonial juga berkumandang keras di Jawa Timur bagian utara. Tampil sebagai pelopor adalah KH. Amin Lamongan, sebagai komandan Hizbullah. ${ }^{18}$ Sepanjang Oktober 1945, Hizbullah terus melakukan konsolidasi dan rekrutmen di berbagai daerah Jawa Tengah, Jawa Timur, Jawa Barat, Jakarta, bahkan Sumatera. Konsolidasi dan pengorganisasian Hizbullah bertitik tolak dari keprihatinan dan kewaspadaan terhadap musuh tiada henti melakukan aksinya dengan tujuan menggagalkan kemerdekaan. ${ }^{19}$

\section{E. Menggempur Pos-pos Pertahanan Pasukan Inggris}

Tentara sekutu Inggris dan NICA mendaratkan 6.000 serdadu dari India pada 25 Oktober 1945 di Surabaya, dengan tujuan mengembalikan Indonesia

${ }^{17}$ Martin Van Bruinessen, NU Tradisi, Relasi-relasi Kuasa, Pencarian Wacana Baru, Op. cit., hlm. 53.

18 Zainul Milal Bizawie, Laskar Ulama-Santri \& Resolusi Jihad Garda Depan Menegakkan Indonesia (1945-1949), Op. cit., hlm. 211.

${ }_{19}$ Zainul Milal Bizawie, Masterpiece Islam Nusantara Sanad dan Jejaring UlamaSantri (1830-1945), Op. cit., hlm. 27. 
kepada Belanda, berdampak para kyai dan santri dari Jawa Timur, Jawa Tengah, dan Jawa Barat, membanjiri kota Surabaya. ${ }^{20}$ Keadaan menjadi semakin keruh pada 27 Oktober 1945 Inggris melalui instruksi Mayjen DC. Hawtorn yang bertindak sebagai panglima AFNEI Inggris untuk Jawa, Madura, Bali, dan Lombok dengan menggunakan pesawat menyebarkan pamflet yang ditujukan kepada penduduk Surabaya. Isi pamflet adalah tentang penegasan terhadap kedudukan dan kekuasaan Inggris di Surabaya. Di dalamnya juga dimuat ketentuan bahwa yang boleh memegang senjata di Surabaya adalah mereka yang menjadi pasukan Inggris dan anggota polisi regular. Di luar ketentuan ini jika ada orang yang memegang senjata, maka Inggris memiliki alasan untuk menembaknya. Pamflet tersebut menimbulkan kemarahan di kalangan penduduk, sedangkan pasukan Inggris mulai menguasai jalan-jalan melakukan perampasan senjata yang ada di tangan para pejuang yang mereka temui. $^{21}$

Pertempuran pun tidak bisa dielakkan lagi. Pihak Surabaya yang semakin lama memendam rasa marah kemudian melakukan penyerbuan terhadap tempat-tempat pasukan Inggris terkonsentrasi. Sekitar tanggal 28-29 Oktober 1945 markas pasukan Inggris dan tentara Gurkha yang berada di Gubeng, Ketabang Kali, Darmo, Sawahan, Bubutan, dan daerah Pelabuhan, telah dikepung oleh rakyat Surabaya yang terbakar semangatnya. ${ }^{22}$ Para pejuang Surabaya yang terdiri dari kesatuan TKR, badan-badan kelaskaran, Hizbullah, hingga penduduk biasa bersatu dalam satu sasaran yaitu menyerang tentara Inggris. Dalam menyukseskan misi ini markas Hizbullah Surabaya yang terletak di Kepanjen dan berhadapan dengan markas pasukan Inggris di sekolah

${ }^{20}$ Ahmad Mansur Suryanegara, Op. cit., hlm. 209.

21 Zainul Milal Bizawie, Laskar Ulama-Santri \& Resolusi Jihad Garda Depan Menegakkan Indonesia (1945-1949), Op. cit., hlm. 214.

${ }^{22}$ Mochammad Ilham, Historiografi Peran Laskar Hizbullah pada Pertempuran 10 November 1945 di Surabaya, UIN Sunan Ampel Surabaya, 2015, digilib.uinsby.ac.id.diunduh pada 06-10-2016 pukul 15.10 WIB. 
Kristen Gatotan, sengaja dikosongkan untuk tujuan penyerangan tersebut. Selanjutnya markas Hizbullah dipindah ke Masjid Kemayoran. ${ }^{23}$

Pada 28 Oktober 1945, para pejuang Surabaya melakukan serangan frontal terhadap pos-pos dan markas pasukan Inggris. Pihak Inggris hanya mengandalkan kekuatannya sekitar 6.000 pasukan dan didukung persenjataan dan peralatan militer modern, namun perlengkapan tersebut masih terlalu kecil dalam menghadapi gelombang serangan dari rakyat Surabaya yang marah dan sebagian dari mereka telah bersenjata. Pada hari ini juga terjadi baku tembak terbuka antara pihak Surabaya dengan pasukan Inggris. Pihak Surabaya yang terdiri dari kesatuan Polisi, TKR, Hizbullah, Barisan Pemberontak Rakyat Indonesia (BPRI), Pemuda Rakyat Indonesia (PRI) serta badan-badan kelaskaran lain di Surabaya dan sekitarnya secara sporadis menggempur pospos pertahanan pasukan Inggris. Laskar Hizbullah Surabaya bersama pejuang lainnya menyerbu pos pertahanan Inggris di Batumiring, demikian halnya dengan pasukan Inggris di Gedung Internatio juga mendapat serangan dari Hizbullah Surabaya Timur. Sementara itu, Hizbullah Surabaya Selatan bersama pejuang lainnya mengepung pasukan Inggris yang berada di Gedung HBS, BPM, stasiun Kereta Api SS, kantor Kawedanan. Sementara kesatuan Hizbullah bantuan dari daerah Sepanjang bersama dengan TKR dan PRI menggempur pasukan Inggris yang bertahan di stasiun kereta api trem OJS Joyolali. $^{24}$

\section{F. Tewasnya Perwira Tentara Sekutu}

Pada 30 Oktober 1945 terjadilah gencatan senjata dicapai oleh dua belah pihak, di mana Inggris diwakili oleh Jenderal Hawtorn dan Jenderal Mallaby sedangkan pihak Surabaya diwakili oleh Soeryo (Gubernur Jawa Timur),

${ }^{23}$ Zainul Milal Bizawie, Laskar Ulama-Santri \& Resolusi Jihad Garda Depan Menegakkan Indonesia (1945-1949), Op. cit., hlm. 214.

${ }^{24}$ Ibid., hlm. 214-215. 
Sudirman (Residen Surabaya), dengan disertai dari badan-badan perjuangan seperti Sungkono dan Bung Tomo. Perundingan sempat berlangsung sengit karena dari perwakilan badan perjuangan menolak dengan keras usulan yang disampaikan Inggris. Meskipun demikian, perundingan berhasil mencapai kesepakatan di mana pihak Inggris mengakui eksistensi Republik Indonesia dan untuk menghindarkan bentrokan di antara kedua belah pihak, pasukan Inggris akan mundur ke pelabuhan Tanjung Perak dan Darmo (Kamp Interniran). Pihak Indonesia sendiri akan mengizinkan para interniran melewati daerah antar kedua sektor itu dengan bebas. Kesepakatan yang lain; diadakan pertukaran masingmasing tawanan, Biro Kontak yang sempat dibentuk ketika pasukan Inggris mendarat pertama kali kembali difungsikan dan dipatuhi oleh kedua pihak, akan dibentuk patroli gabungan, dan larangan membawa snjata yang sebelumnya diberlakukan oleh pihak Inggris kepada masyarakat Indonesia dicabut. Buturanbutiran kesepakatan ini selanjutnya diumumkan melalui radio agar segera diterima dan diketahui penduduk Surabaya. ${ }^{25}$

Sore hari pada 30 Oktober 1945 rombongan Biro Kontak menuju ke Gedung Internatio yang terletak di samping Jembatan Merah, dari sinilah kemudian timbul persoalan karena sekelompok pemuda mendatangi tempat ini dan meminta kepada Biro Kontak agar pasukan Inggris tidak ditempatkan digedung Internatio melainkan di Tanjung Perak, sesuai dengan kesepakatan sebelumnya. Selain itu juga pejuang Surabaya seringkali melihat pasukan Inggris yang terdiri dari pasukan Gurkha di Gedung Internatio itu sering melakukan aksi melepaskan tembakan jika melihat orang Indonesia yang sedang melintas atau sedang berada di sekitar gedung. Dengan melihat sikap yang demikian itu maka pejuang Surabaya tidak percaya terhadap Inggris. Sore itu juga ketegangan kembali meruyak karena terjadi baku tembak antara pasukan

\footnotetext{
${ }^{25}$ Ibid., hlm. 218-219.
} 
Inggris di Gedung Internatio dengan para pejuang Surabaya yang berada di sekitar Jembatan Merah. ${ }^{26}$

Inilah awal dari meletusnya ketegangan yang lebih besar. Dalam bentrokan di sekitar Gedung Internatio tersebut, Brigjen Mallaby tertembak dan mobil yang dikendarainya terbakar. Pimpinan Brigadir ke-49 pasukan Inggris berkebangsaan India itu ditemukan tewas. Tidak jelas yang membuat Mallaby tewas. Kematian Mallaby sontak membangkitkan kemarahan pihak Inggris. Selain marah mereka juga menanggung rasa malu luar biasa karena kehilangan seorang perwira tingginya. ${ }^{27}$

Apa yang terjadi di Surabaya pada Oktober-November 1945 menjadi kisah nyata, kontribusi besar para pejuang dari kaum santri yang bergerak secara gigih, dengan kekuatan lahir batin serta mental baja untuk melawan tentara sekutu. Tidak sedikit yang gugur dalam pertarungan fisik di medan pertempuran untuk menegakkan Indonesia, yang baru saja diproklamasikan kemerdekaannya. Indonesia masih berusia beberapa bulan, yang dihajar oleh tentara sekutu yang tidak ingin negeri ini merdeka dan bebas dari cengkraman pemerintah kolonial. Para santri dan kyai berjuang keras untuk menegakkan negeri. Pertempuran besar tak terhindarkan antara pasukan sekutu dan laskar NKRI yang terdiri dari kyai dan santri. Panglima AFNEI (Allied Forces Netherlands East Indies) Letjen Philip Sir Christison mengirim pasukan Divisi ke-5 di bawah Komando Mayor Jenderal E.C Mansergh, jenderal yang terkenal karena kemenangannya dalam Perang Dunia II di Afrika saat melawan Jenderal Rommel.

\section{G. Peran Laskar Hizbullah dalam Pertempuran 10 November 1945}

\footnotetext{
${ }^{26}$ Ibid., hlm. 220.

${ }^{27}$ Ibid., hlm. 221.
} 
Pada 9 November 1945 tiga pesawat bomber melayang-layang di atas langit Surabaya sambil menyebarkan pamflet berisi ultimatum yang ditandatangani Mayor Jenderal E.C.Mansergh, yang isinya:

Kepada semua Bangsa Indonesia di Surabaya!

Pada tanggal 28 Oktober 1945 rakyat Indonesia di Surabaya secara tidak jujur sekonyong-konyong menyerang angkatan perang Inggris yang datang untuk melucuti dan mengumpulkan angkatan perang Jepang, memberikan bantuan kepada tawanan perang sekutu dan interniran, dan menyelenggarakan keamanan dan ketertiban .

Dalam pertempuran yang berturut terjadi, maka banyak anggota kekuasaan Inggris menjadi korban mati atau luka-luka; ada pula yang hilang. Perempuan dan anak-anak yang diinternir dibunuh secara kejam. Belakangan Brigadir Jenderal Mallaby dibunuh secara tidak jujur, yang pada waktu itu sedang berusaha memegang teguh persetujuan penghentian permusuhan yang telah dilanggar oleh pihak Indonesia tadi.

Kesalahan-kesalahan tersebut di atas tidak dapat dibiarkan begitu saja. Berdasarkan ini saya mengeluarkan perintah yang harus dapat dilakukan. Selanjutnya pada tanggal 10 November 1945 pukul 06.00 akan saya kerahkan semua kesatuan angkatan laut, darat dan udara di bawah komando saya untuk menundukkan orang-orang Indonesia yang mengabaikan perintah saya. Mereka bertanggung jawab atas pertumpahan darah yang dapat dihindarkan.

9 November 1945

Komando Angkatan Darat Sekutu Jawa Timur

Ttd

E.C Mansergh-Mayor Jenderal ${ }^{28}$

Pamflet berisi ultimatum Mayor Jenderal E.C.Mansergh itu disusul instruksi yang juga disebar dari pesawat terbang, yang isinya: (1) pihak Indonesia harus menyerahkan semua tawanan pada tanggal 9 November jam 18.00; (2) semua pimpinan Indonesia harus melaporkan diri pada 9 November 1945 di jalan Jakarta dengan membawa senjata yang diletakkan 100 yard dari tempat berkumpul untuk mendatangi perjanjian menyerah tanpa syarat; (3) a. Bangsa Indonesia lain yang bersenjata harus melaporkan ke Westerbuiten Weg atau ke Darmo BouleVerd dan Coen BouleVerd dengan mengibarkan bendera putih; b. Yang diperkenankan membawa senjata hanya polisi yang berseragam

${ }^{28}$ A. Khoirul Anam, Kisah Ulama: Berjuang dan Mengawal Bangsa untuk Membangun Tradisi Islam Nusantara, Jakarta: Pustaka Compass, 2015, hlm. 27-28. 
dan TKR yang teratur. (4) tentara sekutu akan mengadakan pembersihan di dalam kota dan siapa yang diketahui menyimpan senjata akan dihukum mati; (5) siapa yang mengganggu interniran sekutu akan dijatuhi hukuman mati; (6) para perempuan dan anak-anak Indonesia yang akan meninggalkan kota dibolehkan pada tanggal 9 November 1945 jam 19.00 terbatas pada jurusan Mojokerto dan Sidoarjo lewat jalan besar. ${ }^{29}$

Arek-arek Surabaya meraung marah membaca ultimatum dan instruksi E.C. Mansergh yang sangat merendahkan martabat bangsa Indonesia. Dengan adanya Resolusi Jihad yang dikukuhkan dalam Kongres Umat Islam ${ }^{30}$ pada 78 November 1945 di Yogyakarta, menjadi pegangan moral dan kesatuankesatuan perjuangan Islam dalam menghadapi musuh.

Pertempuran di Surabaya terdengar di seantero tanah air. Laskar Hizbullah berupaya mengerahkan seluruh kekuatannya untuk mendukung penuh pertempurannya di Surabaya. KH. Hasyim Asy'ari sebagai komando tertinggi Laskar Hizbullah menginstruksikan agar pertempuran besar-besaran berikutnya akan dijalankan jika KH. Abbas Buntet, Cirebon telah bergabung. Ia adalah sosok pejuang yang mencintai tanah air, Negara Kesatuan Republik Indonesia. Ia menggembleng santri agar semangat memperjuangkan agama dan Negara. Bahkan, Buntet Pesantren juga menjadi markas latihan Laskar Hizbullah, Sabilillah, dan pasukan Peta. Ia juga membentuk dua regu laskar santri, yang dinamakan Asybal dan Athfal. ${ }^{31}$

\section{${ }^{29}$ Ibid., hlm. 28.}

${ }^{30}$ Kongres juga sepakat untuk menempatkan KH.Hasyim Asy'ari sebagai Ketua Masyumi dan KH.Wahab Chasbullah sebagai wakilnya. Dalam struktur pengurus besarnya terpilih Sukiman Wiryosanjoyo sebagai Ketua Umum Masyumi dengan dibantu KH.Wahid Hasyim, Mr. Syafruddin prawiranegara, Mr. Mohammad Roem, Yusuf Wibisono, KH. Fakih Usman, Anwar Cokroaminoto, dan lain lain. Sementara puncak pimpinan kesatuan Hizbullah masih tetap dipercayakan kepada KH. Zainul Arifin, dan pimpinan tertinggi Sabilillah juga tetap dipercayakan kepada KH. Masykur. Lihat Zainul Milal Bizawie, Laskar Ulama-Santri \& Resolusi Jihad Garda Depan Menegakkan Indonesia (1945-1949), Op. cit., hlm. 221-222.

${ }^{31}$ Munawir Aziz, Pahlawan Santri Tulang Punggung pergerakan Nasional, Op. cit., hlm. 41. 
Laskar Hizbullah merupakan kekuatan yang tangguh dan disegani musuh. Di Cirebon muncul tokoh Hizbullah seperti KH. Hasyim Anwar dan KH. Abdullah Abbas. ${ }^{32}$ Ketika melakukan perang gerilya, tentara Hizbullah memusatkan perhatiannya di daerah Legok, kecamatan Cidahu, kabupaten Kuningan, dengan front di perbukitan Cimaneungteung yang terletak di daerah Waled Selatan. ${ }^{33}$ Tercatat dalam sejarah Indonesia dan sejarah Pondok Pesantren Buntet sendiri, bahwa pada pertempuran 10 November 1945 di Surabaya peran KH. Abbas bersama KH. Annas dalam perjuangan melawan imperialis Inggris sangat menentukan nasib bangsa Indonesia. Atas restu KH. Hasyim Asy'ari, Kyai Abbas terlibat langsung dan bahu membahu dengan para pejuang lainnya dalam pertempuran tersebut. Bahkan ketika bung Tomo datang berkonsultasi kepada KH. Hasyim Asy'ari untuk meminta persetujuan perlawanan rakyat terhadap imperialis Inggris ia menyarankan agar perlawanan rakyat itu jangan dimulai lebih dahulu sebelum KH. Abbas datang ke Surabaya. $^{34}$

Bung Tomo juga berhasil mengobarkan spirit perlawanan dengan serangkaian pidatonya yang bersemangat melalui Radio Pemberontakan Rakyat Indonesia pada 9 November 1945, pecahlah pertempuran yang tidak dapat dihindarkan lagi. ${ }^{35}$ Bung Tomo memiliki hubungan yang baik dengan kelompok Islam. Ia telah memperoleh kepercayaan dan dukungan dari $\mathrm{KH}$. Wahid Hasyim. Bung Tomo juga sering bertemu dengan para kyai untuk

${ }^{32}$ Pada 1 Maret 1946 telah diresmikan markas Batalyon Hizbullah sebagai Batlyon II, Resimen II, Divisi Syarif Hidayatullah berkedudukan di Mundu Pesisir kecamatan Astanajapura, kabupaten Cirebon dengan pimpinan komandan batalyon KH. Hasyim Anwar, wakil komandan batalyon Rachmat Hasyim, kepala staf batalyon KH. Abdullah Abbas. Lihat Ahmad Zaini Hasan, Perlawanan Dari Tanah Pengasingan, Yogyakarta: Lkis, 2014, hlm. 101102.

33 Zainul Milal Bizawie, Laskar Ulama-Santri \& Resolusi Jihad Garda Depan Menegakkan Indonesia (1945-1949), Op. cit., hlm. 224.

${ }^{34}$ Mastuki HS, dan M. Ishom El-Saha, Intelektualisme Pesantren "Potret Tokoh dan Cakrawala Pemikiran di Era Perkembangan Pesantren”, Jakarta: Diva Pustaka, 2004, hlm. 255 .

${ }^{35}$ Ahmad Mansur Suryanegara, Op. cit., hlm. 209. 
mendapatkan pesan-pesan yang kemudian digunakan sebagai bahan materi dalam serangkaian pidatonya untuk menggugah semangat dalam berjuang melawan musuh.

Surabaya menjadi medan pertempuran yang cukup menghentakkan pihak sekutu. Surabaya menjadi Melting Pot Laskar Hizbullah dari berbagai daerah. Dengan berbekal Fatwa Jihad yang diteguhkan Resolusi Jihad, para pejuang pantang mundur menolak kedatangan kolonial. ${ }^{36}$

Malam 10 November 1945 menjadi malam yang sibuk dan menegangkan. Semua unsur-unsur perjuangan telah mempersiapkan diri di posisinya masing-masing untuk menunggu komando bertempur. Badan perjuangan Islam masih mempertahankan formasi Hizbullah, Sabilillah, GPII dari daerah-daerah lain di Jawa Timur, bahkan dari Jawa Tengah dan Jawa Barat. Jumlah itu semakin berlipat-lipat karena banyak pesantren di Jawa yang turut mengirimkan para santrinya untuk ikut bertempur. Dari Jawa Barat, terutama dari Pesantren Buntet, Cirebon melalui himbauan KH. Abbas dikirim ribuan santri yang tergabung dalam Hizbullah dan Sabilillah di Cirebon dan sekitarnya untuk menambah kekuatan kaum revolusional Surabaya. Kota Surabaya diupayakan kosong dari penduduk biasa, orang tua, wanita dan anak-anak sehingga berlangsung pengungsian besar-besaran ke arah selatan. Namun, sebagian penduduk kota dan kalangan remaja, mereka menolak untuk mengungsi karena ingin menjadi bagian dalam usaha mempertahankan kota dan ingin membantu laskar-laskar perjuangan republik terhadap serangan besar-besaran pasukan Inggris. ${ }^{37}$

Dalam pertempuran tanggal 12 November 1945, pihak pejuang berhasil menembak dua pesawat tempur Inggris hingga hancur bersama penumpang di

${ }^{36}$ Zainul Milal Bizawie, Masterpiece Islam Nusantara Sanad dan Jejaring UlamaSantri (1830-1945), Op. cit., hlm. 27-28.

37 Zainul Milal Bizawie, Laskar Ulama-Santri \& Resolusi Jihad Garda Depan Menegakkan Indonesia (1945-1949), Op. cit., hlm. 227. 
dalam pesawat yang di antaranya adalah Brigadir Jenderal Robert Guy Loder Simons. Serangkaian serangan awal besar-besaran yang dilakukan Inggris itu tercatat ribuan orang yang menjadi korban. Para korban tidak hanya orang Indonesia saja melainkan juga orang asing yang tinggal di Surabaya seperti penduduk etnis China. Jatuhnya korban dari penduduk etnis China ini kemudian menggerakkan para pemuda China juga ikut bergabung dan berjuang bersama pejuang Republik dalam menghadapi gempuran pasukan Inggris. $^{38}$

Pada hari ketiga pertempuran, 13 November 1945, pihak pejuang Surabaya mulai mengatur tugas-tugas pertempuran. Pimpinan perlawanan menyadari benar karena ketiadaan pengaturan tugas pertempuran ini maka Inggris dengan mudahnya melakukan serangannya dalam tiga hari pertama. Pengaturan tugas pertempuran adalah bagian tugas tempur masing-masing sektor di Surabaya dengan sektor timur, sektor tengah, dan sektor barat. Pada masing-masing sektor ini terdapat gabungan kesatuan perlawanan yang terdiri dari TKR, BKR, Polisi, Hizbullah, Sabilillah, BPRI dan badan-badan perjuangan lainnya. Kesatuan Hizbullah secara institusi dalam pembagian tugas pertempuran ditempatkan di sektor tengah dan sektor barat. Di sektorsektor ini kesatuan Hizbullah dan Sabilillah tergabung dengan badan-badan perjuangan lain seperti persatuan TKR Divisi VII Surabaya, Jombang, Mojokerto, kesatuan polisi, Laskar BPRI, Laskar Buruh, dan sebagainya. Memang belum ada informasi yang jelas mengenai bagaimana komando pada masing-masing sektor berbagi tugas, namun dengan mengacu kepada pembagian seksi-seksi Hizbullah yang terbentuk pada bulan Oktober 1945 maka akan didapatkan gambaran bahwa kesatuan Hizbullah Surabaya dan Surabaya bagian tengah yang masing-masing dipimpin oleh KH. Abdunnafik Achyar dan Husaini Tiway serta Moh. Muhadjir bergabung dengan kesatuan

\footnotetext{
${ }^{38}$ Ibid., hlm. 230.
} 
TKR yang bergabung dalam Resimen TKR Devisi VII di bawah pimpinan Marhadi dan Resimen TKR Devisi VII pimpinan Mayor Kretarto. Bersama mereka juga bergabung kesatuan BPRI dan badan-badan kelaskaran lainnya. Gabungan badan-badan perjuangan ini yang menghadapi dan bertempur melawan pasukan Inggris di area tengah kota Surabaya. ${ }^{39}$

Selanjutnya kesatuan Hizbullah Surabaya Timur pimpinan Mustakim Zain dan Syaban Abbas tersatukan dengan kesatuan TKR pimpinan Mayor Kadim dengan pusat komandonya di Karangmenjangan. Gabungan badan perjuangan di sektor ini selain TKR dan Hizbullah juga diisi unsur-unsur perjuangan yang jumlahnya sangat banyak seperti ALRI, BPRI, Pesindo (Pemuda Sosialis Indonesia), PRI, TKR Malang, Taruna AL, dan Batalyonbatalyon dari TKR Surabaya dan masing-masing dipimpin Sunandar, Sucipto, Bambang Yuwono, Isa Edris, dan sebagainya. Adapun di sektor barat, area tugas pertempuran di bawah komando Kunkyat yang di dalamnya terdapat kesatuan Hizbullah Surabaya barat pimpinan Damiri Ichsan dan Abdul Hamid. Mereka bergabung bersama TKR Surabaya, TKR Bojonegoro, dan kesatuan TKR lain serta di dalamnya bergabung juga Laskar Buruh dan badan-badan perjuangan lain. ${ }^{40}$

Pada 24-25 November 1945 pasukan Inggris akhirnya menguasai seluruh kota Suarabaya atau setelah dua minggu penuh bertempur tanpa henti. Keberhasilan ini juga bukan dikarenakan para pejuang Republik berhasil dihancurkan, namun lebih karena adanya himbauan pimpinan perlawanan untuk mengundurkan diri dari kota. Para pejuang mengundurkan diri selain menghindarkan jumlah korban yang tidak perlu, juga ditunjukkan untuk mengatur lagi strategi perlawanan. Untuk itu, dibentuk markas pimpinan pejuang yang berpusat di Mojokerto yang melahirkan dewan Perjuangan

\footnotetext{
${ }^{39}$ Ibid., hlm. 230-231.
}

${ }^{40}$ Ibid., hlm. 231. 
Rakyat Surabaya. Dewan ini yang mengatur koordinasi tiga front pertempuran; utara, tengah, dan selatan. ${ }^{41}$

Pertempuran berlangsung dengan ganas selama tiga minggu. Pada akhir bulan November 1945 seluruh kota telah jatuh ke tangan sekutu. Namun semangat perlawanan para pejuang Indonesia yang masih hidup tak bisa dipadamkan. Para santri, dan tentara mengikuti ribuan pengungsi yang melarikan diri meninggalkan Surabaya dan kemudian mereka membuat garis pertahanan baru mulai dari Mojokerto di barat hingga ke arah Sidoarjo di timur. Beberapa versi menyebut, korban dari pihak Republik Indonesia mencapai 20.000 bahkan hingga 30.000 jiwa. $^{42}$

\section{H. Meleburnya Laskar Hizbullah dalam TNI}

Terkait dengan semakin banyaknya pasukan Belanda yang masuk ke dalam wilayah Indonesia, maka pihak Republik mengambil sikap yang lebih militan. Pada 1 Januari 1946 Kementrian Keamanan diganti namanya menjadi Kementerian Pertahanan dengan mendapatkan tanggung jawab yang lebih luas, yakni menangani pertahanan. Pada saat yang bersamaan, Tentara Keamanan Rakyat (TKR) diubah namanya menjadi "Tantara Keselamatan Rakyat". Namun nama ini ternyata masih belum memuaskan, dan pada 24 Januari 1946 TKR (Keselamatan Rakyat) diganti nama baru menjadi Tentara Republik Indonesia (TRI). ${ }^{43}$

Pada 23 Februari 1947 Kementerian Pertahanan membentuk sebuah Panitia Besar Penyelenggaraan Organisasi Tentara yang bertugas untuk menyusun peraturan tentang hal-hal yang berkaitan dengan urusan pertahanan, organisasi tentara, peralihan dari TKR menjadi TRI, dan kedudukan laskar-

${ }^{41}$ Ibid., hlm. 234.

${ }^{42}$ A. Khoirul Anam, Kisah Ulama: Berjuang dan Mengawal Bangsa untuk Membangun Tradisi Islam Nusantara, Op. Cit., hlm. 27-28.

43 Zainul Milal Bizawie, Laskar Ulama-Santri \& Resolusi Jihad Garda Depan Menegakkan Indonesia (1945-1949), Op. cit., hlm. 286-287. 
laskar perjuangan. Berdasarkan peraturan yang dikeluarkan oleh pihak Kementerian Pertahanan dinyatakan bahwa badan-badan kelaskaran dalam struktur Kementerian Pertahanan berada dalam penanganan sebuah biro, yaitu Biro Pertahanan. ${ }^{44}$

Panglima Besar TRI Jenderal Sudirman memberikan penghargaan kepada kesatuan Hizbullah sambil terus menghimbau agar kesatuan Hizbullah tetap menjaga semangat perlawanannya kepada musuh. Hal ini disampaikan Panglima TNI dalam sebuah amanatnya yang khusus ditujukan kepada kesatuan Hizbullah dan Sabilillah yang termaktub dalam enam pasal:

1. Percaya kepada kekuatan diri sendiri dan kebesaran keadilan Tuhan.

2. Meneruskan perjuangan dalam menuntut dan membela kebenaran dan keadilan.

3. Jangan sekali-kali menyerah kepada siapapun juga, berusaha menjaga kemerdekaan nusa, bangsa, dan agama.

4. Mempertahankan proklamasi Indonesia merdeka dan menjaga kesatuan Negara Republik Indonesia dengan segenap jiwa dan raga.

5. Mendalamkan sungguh-sungguh disiplin tentara.

6. Hidup sebagai solikhin dan mati sebagai suhada. ${ }^{45}$

Berdasarkan peraturan No. 19 tentang Biro Perjuangan dan Maklumat Menteri Pertahanan tanggal 4 Oktober 1946 tentang pembentukan Dewan Kelaskaran Pusat dan Dewan Kelaskaran Daerah yang dipimpin oleh Biro Perjuangan, maka pada 12 November 1946 KH. Zainul Arifin menjadi salah satu pengurusnya, ia disibukkan dengan proses peleburan Laskar Hizbullah, Sabilillah, dan Tentara Keamanan Rakyat (TKR) ke dalam wadah tunggal TNI (Tentara Nasional Indonesia). ${ }^{46}$

\footnotetext{
${ }^{44}$ Ibid., hlm. 287-288.

${ }^{45}$ Ibid., hlm. 289.

${ }^{46}$ Ario Helmy, Op. cit., hlm. 59.
} 
Usaha untuk penyempurnaan terus dilakukan oleh Pemerintah Indonesia terhadap angkatan bersenjata. Banyaknya laskar-laskar dan badan perjuangan rakyat mengakibatkan sering terjadi salah faham. Pada 5 Mei 1947 Presiden Soekarno mengeluarkan penetapan tentang penyatuan TRI dengan badan dan laskar perjuangan menjadi satu organisasi tentara. Pada 3 Juni 1947 Presiden Soekarno meresmikan penyatuan TRI dengan laskar-laskar perjuangan menjadi satu wadah tentara nasional dengan nama Tentara Nasional Indonesia. Presiden juga menetapkan Jenderal Soedirman sebagai Kepala Pimpinan TNI. Dalam ketetapan itu juga menyatakan bahwa semua Angkatan Perang dan satuan laskar yang menjelma menjadi TNI, diwajibkan untuk taat dan tunduk kepada segala perintah dari instruksi yang dikeluarkan oleh Pucuk Pimpinan TNI. ${ }^{47}$

Hizbullah menanggapi secara positif keinginan dari pemerintah. Hizbullah menjadi salah satu laskar perjuangan yang tidak terlalu mempermasalahkan himbauan pemerintah dan tidak berselang lama menyatakan diri bergabung dengan TNI. Hizbullah lebih memilih mengikuti langkah pemerintah dan pimpinan TNI dengan berbagai pertimbangan, di antaranya karena keterbatasan persenjataan yang dimiliki, dan sikap positif terhadap kebijakan otoritas pertahanan, terlebih kepada Markas Besar TNI yang selalu mengadakan pembenahan. Namun begitu, dalam internal HIzbullah sempat muncul penolakan terhadap upaya penggabungan ketika kesatuan reguler masih bernama TRI. Sikap ini ditunjukkan oleh kesatuan Hizbullah yang bergabung dalam Hizbullah Sunan Ampel di bawah pimpinan Mayor Mansur Solichy karena khawatir dengan penggabungan itu maka Hizbullah nantinya akan diperlakukan seperti anak tiri. Namun sikap

47 Zainul Milal Bizawie, Laskar Ulama-Santri \& Resolusi Jihad Garda Depan Menegakkan Indonesia (1945-1949), Op. cit., hlm. 290-291. 
Hizbullah Sunan Ampel ini melunak ketika TRI diubah menjadi TNI, sikap ini mengundang rasa simpati Panglima TNI Jenderal Sudirman. ${ }^{48}$

Pada 15 Mei 1947 dalam Konferensi Pimpinan Hizbullah se-Jawa dan Madura telah dicapai kesepakatan bahwa Hizbullah menyatakan diri masuk ke dalam institusi TNI. Keputusan ini diambil untuk menyikapi dan mengikuti Dekrit Pemerintah pada 4 April 1947 yang meminta agar badan-badan kelaskaran dan TRI bergabung dalam TNI. Sebagai tindak lanjut, pada 15 Juni 1947 seluruh jajaran pimpinan pusat Hizbullah mengadakan Konferensi Hizbullah se-Jawa dan Madura di Yogyakarta. Hasil konferensi didapatkan keputusan aklamasi bahwa Hizbullah bergabung ke dalam TNI. Kesatuankesatuan Hizbullah dalam TNI melebur dalam kesatuan-kesatuan setingkat brigade, resimen, batalyon, dan seksi pasukan dalam organisasi TNI. ${ }^{49}$

Dalam keterangan KH. Saifuddin Zuhri, perundingan tingkat tinggi antara pimpinan kelaskaran dengan pihak pemerintah dicapai suatu keputusan, bahwa tidak semua anggota kelaskaran dilebur dalam TNI. Pemerintah menetapkan, bahwa Hizbullah mendapat satu batalyon dalam satu divisinya. KH.Wahib Wahab menyerahkan Batalyon Munasir menjadi TNI, Munasir menjadi komandan dengan pangkat Mayor. Sedangkan divisi yang dipimpin oleh KH.Saifuddin Zuhri menyerahkan Batalyon Suroso menjadi TNI, Suroso sebagai komandan. Begitu juga dengan divisi-divisi Hizbullah di beberapa daerah yang menyerahkan satu atau dua batalyon kepada TNI. Sebenarnya program Menteri Amir Syarifuddin ini ditentang oleh KH. Wahid Hasyim, karena dianggap sebagai strategi untuk menyiapkan barisan komunis. ${ }^{50}$

\footnotetext{
${ }^{48}$ Ibid., hlm. 291.

${ }^{49}$ Ibid., hlm. 291-292.

${ }^{50}$ Munawir Aziz, Pahlawan Santri Tulang Punggung pergerakan Nasional, Op. cit.,
} hlm. 64. 
Ketika program nasionalisasi TNI, sebagian besar anggota TNI yang berasal dari laskar rakyat "tersingkir", meski sebenarnya lebih banyak lagi anggota Hizbullah dan Sabilillah yang mengundurkan diri karena berbagai alasan di antaranya, pertama, jihad fisik membela tanah air sudah usai, sehingga para santri dan ulama kembali mengelola pondok-pondok pesantren dan lembaga-lembaga pendidikan yang terbengkalai selama perang. Kedua, dengan program pelatihan kembali kepada anggota laskar rakyat yang ingin melanjutkan dinas militer, menyebabkan banyak anggota laskar yang berguguran. Apalagi ada syarat harus bisa berbahasa Belanda untuk mengikuti pelatihan perwira di Belanda. Akibatnya, hanya perwira-perwira dari KNIL dan sebagian kecil Peta yang lulus. Meskipun demikian, unsur Peta pada akhirnya "tersingkir" juga setelah wafatnya Panglima Besar Sudirman, 29 Januari 1950. Selanjutnya, di era 1950-an pimpinan TNI didominasi unsur KNIL dan perwira-perwira yang menerima pendidikan militer dari Belanda dan Negara barat lainnya. ${ }^{51}$

Dalam proses kelahiran militer Indonesia, peran laskar-laskar santri yang dipimpin para kyai, ulama, dan ajengan, harus dicatat dengan tinta emas sebagai “ibu kandung” yang melahirkan TNI. Meski dalam perjalanannya, terdapat banyak persoalan politik, berkaitan dengan perbedaan ideologi Negara dan ideologi laskar, serta persoalan organisasi TNI, tetapi tidak seharusnya pengorbanan laskar santri ini dinafikan begitu saja.

\section{Penutup}

Kedahsyatan pertempuran 10 November 1945 di Surabaya tidak bisa dilepaskan dari Resolusi Jihad 22 Oktober 1945. Resolusi jihad tidak hanya sebagai pengobar semangat ulama-santri, tetapi juga bertujuan untuk mendesak pemerintah agar segera menentukan sikap melawan kekuatan asing

${ }^{51}$ Syafi'i Ma'arif, dkk, Menggugat Sejarah, Bandung: Sega Arsy, 2010, hlm. 24. 
yang ingin menggagalkan kemerdekaan. Banyak terjadi pertempuranpertempuran yang melibatkan para kyai dan santri yang tergabung dalam Laskar Hizbullah. Surabaya menjadi medan pertempuran yang cukup menghentakkan pihak sekutu. Surabaya menjadi Melting Pot Laskar Hizbullah dari berbagai daerah. Pertempuran berlangsung dengan ganas selama tiga minggu. Pada akhir bulan November 1945 seluruh kota telah jatu ke tangan sekutu. Namun semangat perlawanan para pejuang Indonesia yang masih hidup tak bisa dipadamkan. 


\section{DAFTAR PUSTAKA}

\section{Buku-buku:}

Al Anshori, M. Junaedi. Sejarah Nasional Indonesia: Masa Prasejarah sampai Masa Proklamasi Kemerdekaan. Jakarta: PT Mitra Aksara Panaitan. 2010.

Amin, Zamzami. Baban Kana Pondok Pesantren Babakan Ciwaringin dalam Kancah Sejarah untuk Melacak Perang Nasional Kedongdong 18021919. Bandung: Pustaka Aura Semesta. 2014.

Anam, Khoirul. Kisah Ulama: Berjuang dan Mengawal Bangsa untuk Membangun Tradisi Islam Nusantara. Jakarta: Pustaka Compass. 2015.

Aziz, Munawir. Pahlawan Santri Tulang Punggung pergerakan Nasional. Ciputat: Pustaka Compass. 2016.

Bizawie, Zainul Milal. Laskar Ulama-Santri \& Resolusi Jihad Garda Depan Menegakkan Indonesia (1945-1949). Jakarta: Pustaka Compass. 2014.

Bizawie, Zainul Milal. Masterpiece Islam Nusantara Sanad dan Jejaring Ulama-Santri (1830-1945). Jakarta: Pustaka Compass. 2016.

Bruinessen, Martin Van. NU Tradisi, Relasi-relasi Kuasa, Pencarian Wacana Baru. trj. Farid Wajidi. Yogyakarta: LKiS. 1994.

Bustami, Abdul Latif. Resolusi Jihad "Perjuangan Ulama: Dari Menegakkan Agama Hingga Negara”. Jombang: Pustaka Tebuireng. 2015.

Hasan, Ahmad Zaini. Perlawanan Dari Tanah Pengasingan. Yogyakarta: LkiS. 2014.

Helmy, Ario. KH. Zainul Arifin Pohan Panglima Santri Ikhlas Membangun Negeri. Tangerang: Pustaka Compass. 2015.

HS, Mastuki dan M. Ishon El-Saha. Intelektualisme Pesantren. Jakarta: Diva Pustaka. 2004.

Kurasawa, Aiko. Masyarakat dan Perang Asia Timur Raya. Depok: Komunitas Bambu. 2016. 
Ma'arif, Syafi'I, dkk. Menggugat Sejarah. Bandung: Sega Arsy. 2010.

Madjid, M. Dien dan Johan Wahyudhi. Ilmu Sejarah: Sebuah Pengantar. Jakarta: Kencana. 2014.

Muljana, Slamet. Kesadaran Nasional Dari Kolonialisme sampai Kemerdekaan. Jilid II. Yogyakarta: LKiS. 2008.

Oktorino, Nino. Di Bawah Matahari Terbit: Sejarah Pendudukan Jepang di Indonesia 1941-1945. Jakarta: PT Gramedia. 2016.

Poeponegoro, Marwati Djoenoed \& Nugroho Notosusanto. Sejarah Nasional Indonesia VI. Jakarta: Departemen Pendidikan \& Kebudayaan dan Balai Pustaka. 1993.

Ricklefs, Mc. Sejarah Indonesia Modern 1200-2008. Jakarta: Serambi. 2008.

Sulasman. Metodologi Penelitian Sejarah Teori, Metode, Contoh Aplikasi. Bandung: Pustaka Setia. 2014.

Suryanegara, Ahmad Mansur. Api Sejarah 2. Bandung: Salamadani. 2010.

Sztompka, Piötr. Sosiologi Perubahan Sosial. trj. Alimandan. Jakarta: Prenada. 2007.

Tim Penyusun. Ensiklopedi Islam Indonesia. Jakarta: PT. Ikhtiar Baru Van Houve. 1993.

Qomar, Mujamil. Pesantren Dari Transformasi Metodologi Menuju Demokratisasi Institusi. Jakarta: Erlangga. 2009.

Zuhri, Saifuddin. Berangkat Dari Pesantren. Jakarta: Gunung Agung. 1987.

\section{Skripsi dan Hasil Penelitian:}

Hasanah, Nur.Perjuangan Laskar Hizbullah Klaten dalam Menghadapi Agresi Militer Belanda II Tahun 1949. 2010. digilib.uin-suka.ac.id. diunduh pada 06-10-2016 pukul 15.23 WIB. 
Ilham, Mochammad. Historiografi Peran Laskar Hizbullah pada Pertempuran 10 November 1945 di Surabaya. 2015. digilib.uinsby.ac.id. diunduh pada 06-10-2016 pukul 15.10 WIB.

Miftahuddin, dkk. Peran Organisasi Islam: Dari Perjuangan Menuju Kemerdekaan Masa Perang Kemerdekaan (1936-1946). 2012. staff.uny.ac.id. diunduh pada 06-10-2016 pukul 15.07 WIB.

Mutiana, Tia. Barisan Hizbullah Keresidenan Semarang Tahun 1944-1947. 2015. lib.ui.ac.id. diunduh pada 06-10-2016 pukul 15.19 WIB. 